\title{
OCCURRENCE OF THE ENDANGERED GOLD-EDGED GEM (SCHINIA AVEMENSIS) AT CFB SUFFIELD NATIONAL WILDLIFEAREA, ALBERTA
}

OLAF JENSEN and MEDEA CURTEANU, Environment Canada, Canadian Wildlife Service, Room 200, 4999 98 ${ }^{\text {th }}$ Avenue NW, Edmonton, AB, T6B 2X3, and GARY ANWEILER, $7212103^{\text {rd }}$ Avenue, Edmonton, AB, T6A 0V1

\section{Introduction}

The Gold-edged Gem (Schinia avemensis Hooper) is a small (16-20 $\mathrm{mm}$ wingspan) day-flying flower moth. Its forewings are greenish-brown and maroon, crossed by two partial yellow bands, with a prominent yellow band along most of the outer edge of the forewing. There are no named subspecies, and the egg, larval, and pupal stages have not been described. ${ }^{1}$ The Gold-edged Gem is currently listed as Endangered by the Committee on the Status of Endangered Wildlife in Canada (COSEWIC), meaning it faces imminent extirpation or extinction.

Gold-edged Gems have a very restricted and disjunct distribution in the arid regions of central North America; occupied sites are known to occur at one location each in Manitoba and Saskatchewan, two locations in
Alberta, and three sites in Colorado. Figure 1 shows the recorded locations of Gold-edged Gems in North America (the third location in Colorado is obscured on the map by the more northerly location in that state); the three black dots in the Canadian Forces Base (CFB) Suffield National Wildlife Area (the dark grey area within CFB Suffield) are new observations. Table 1 contains detailed location information.

Gold-edged Gems are found in close association with their larval host plant, the Plains Sunflower (Figure 2, see inside back cover). In addition to obtaining nectar from the host plant, Rush Skeletonplant is an important and perhaps primary nectar source used by adult moths. ${ }^{2}$ Gold-edged Gems have been found only within active sand dunes and blow-outs in close association with the larval host plant.

Table 1. North American locations of Gold-Edged Gems

\begin{tabular}{lcccl}
\hline \multicolumn{1}{c}{ Location } & Lat & Long & Observation & Source \\
\hline CFB Suffield National Wildlife Area, AB & 50.32034 & -110.67806 & 2008 & Direct - GPS obtained by authors \\
CFB Suffield National Wildlife Area, AB & 50.62804 & -110.31678 & 2008 & Direct - GPS obtained by authors \\
CFB Suffield National Wildlife Area, AB & 50.51340 & -110.46063 & 2008 & Direct - GPS obtained by authors \\
Pakowki Lake, AB & 49.39800 & -110.87500 & 2005 & University of Alberta - Strickland Museum \\
Red Deer River, Bindloss, AB & 50.93800 & -110.41400 & 2004 & University of Alberta - Strickland Museum \\
Spruce Woods Provincial Park, MB & 49.66300 & -99.28700 & 2004 & University of Alberta - Strickland Museum \\
Burstall, SK & 50.70000 & -109.90800 & 2004 & University of Alberta - Strickland Museum \\
Great Sand Dunes NP, Colorado & 37.73467 & -105.51000 & & Direct - GPS obtained by Charles Harp \\
Great Sand Dunes NP, Colorado & 37.75267 & -105.51000 & & Direct - GPS obtained by Charles Harp \\
2.5 mi NE of Roggen, Colorado & 40.19533 & -104.50583 & & Direct - GPS obtained by Charles Harp \\
\hline
\end{tabular}




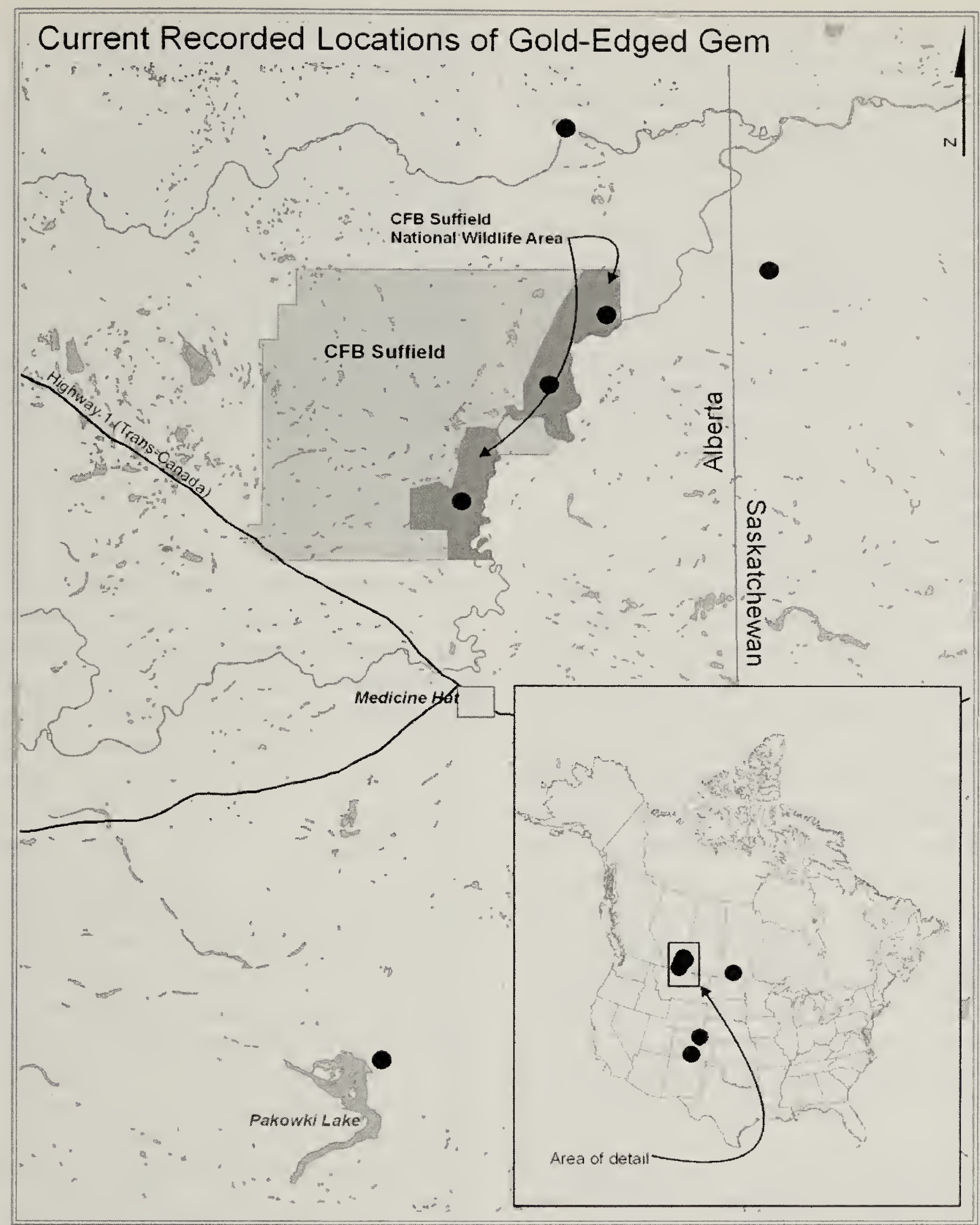

Figure 1. North American distribution of the Gold-edged Gem

In Canada, they are active throughout much of the day, from approximately 10 July to 20 August.

The main threat to the Gold-edged Gem is believed to be the loss of habitat resulting from stabilization of active sand dunes. ${ }^{1}$ Active sand dunes are progressively becoming stabilized as a result of the current climatic conditions in combination with changes in fire and grazing regimes. ${ }^{3.4}$ Loss of habitat from the encroachment of native and invasive species is also a concern; ${ }^{1}$ both Crested Wheatgrass and Baby's-breath were observed in the dune complex at Pakowki Lake in southern Alberta, as was Sweet-clover at the Spruce Woods site in Manitoba, both of which are active Gold-edged Gem habitats. The establishment of these non-native invasive species may 
lead to the stabilization of dunes and the loss of native sunflowers and Skeleton Weed through competition. 5,6 It is also possible that the creation of roads or trail edges with Prairie Sunflowers in proximity to existing habitat may create sink habitat that further depresses local populations by drawing individuals of this species to areas where they may be subject to mortality from vehicle collisions or road grading. However, little is known about the specific factors affecting the conservation status of the Gold-edged Gem in Canada.

The CFB Suffield National Wildlife Area (NWA) is a $458-\mathrm{km}^{2}$ reserve of native grassland, active sand dunes, and coulees along the South Saskatchewan River in the grasslands of south-eastern Alberta. The two previously known Gold-edged Gem colonies in Alberta, at Pakowki Lake and along the Red Deer River north of Bindloss, are located south and north of the NWA, respectively. Between these two locations lie the Middle Sand Hills, which occur within the boundaries of the NWA. The purpose of this study was to determine whether the Gold-edged Gem occurs in CFB Suffield. The only other report of the Gold-edged Gem in Alberta is a historical specimen in the University of Alberta Strickland Museum collection labelled "Medicine Hat," which may have come from the Middle Sandhills, the closest dune habitat to Medicine Hat.

\section{Methods}

On 11-12 August 2008, after determining that Gold-edged Gems were active at the Pakowki Lake site, potential habitat in the CFB Suffield NWA (i.e., active sand areas with blooming native sunflowers) was visited and searched for adult Gold-edged Gems. Several areas of the NWA with active dune habitat were searched, including
Amiens, Ypres, and Casa Berardi. An estimated $90-95 \%$ of the blossoms in or adjacent to active dunes were examined for resting adult moths, an effective method of locating Goldedged Gems at other sites (G. Anweiler, pers. obs.). ${ }^{1}$

\section{Results}

Single adult Gold-edged Gems were found at all three locations in the CFB Suffield NWA (Table 1): at the Dugway Dunes in area Casa Berardi at 522919E 5574298N, in the Middle Sand Hills in area Amiens at 548323E $5608686 \mathrm{~N}$, and in area Ypres at $538242 \mathrm{E} 5595854 \mathrm{~N}$ (all locations are UTM 12 NAD 83). We searched an additional four dunes in area Ypres (537800E 595600N) and Amiens (547800E $5607100 \mathrm{~N}, \quad 545800 \mathrm{E}$ $5608800 \mathrm{~N}, 544100 \mathrm{E} 5606300 \mathrm{~N})$ but found no Gold-edged Gems.

\section{Discussion}

Gold-edged gems were observed in large numbers (more than 50 individuals) at the Pakowki Lake site, located approximately $100 \mathrm{~km} \mathrm{SSW}$ of CFB Suffield. However, only single individuals were observed at the three sites where gems were found in the NWA. The difference in numbers observed may be attributable to differences in the amount and distribution of suitable habitat. Pakowki Lake comprises an extensive field of open dunes that are interconnected or separated by only small parcels of grassland vegetation. Cattle grazing in the area may be contributing to the maintenance of these dunes by removing vegetation and disturbing the soil. The sunflower colonies at the Pakowki dunes appeared to be larger and more numerous than at Suffield NWA. The active dunes at Suffield NWA are relatively small and separated by greater distances, which may limit dispersion and colonization of these areas. Additionally, it was our 


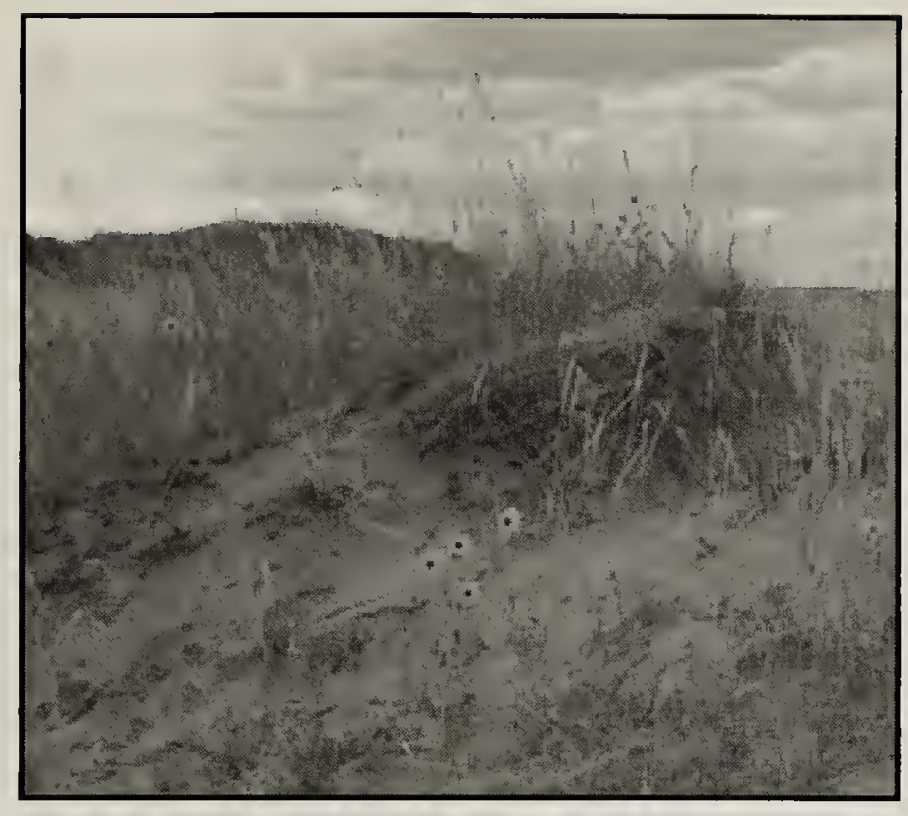

Figure 3. Habitat of adult Gold-edged Gem at CFB Suffield National Wildlife Area

impression that sunflowers at the NWA were more thinly distributed over larger areas and also along the numerous disturbed roadsides. At the Pakowki Lake site, the colonies contained greater densities of plants in relatively discrete colonies within the active dunes themselves.

\section{Observations of habitat} characteristics suggest that the Goldedged Gem may not only be a specialist with respect to macro-habitat features (sand dunes) but also micro-habitat features of these dunes. The only Goldedged Gems we found on dunes at Suffield were located on small, sandy, partially vegetated slopes on the lee side of the dune (SE-facing slopes) in small concave depressions (Figure 3 ). We did not find the species in the relatively larger depressions within the dune where sand was actively being eroded by wind action.

The fact that only a few individual Gold-edged Gems were found within the Suffield NWA does not necessarily indicate that this is an insignificant population. More extensive and systematic surveys over a period of years are needed to determine the size of the Suffield population. Currently, two of the three Alberta sites with Gold- edged Gems are on public lands and thus are offered some legislated protection. The Pakowki Dunes are Provincial crown land managed by Alberta Sustainable Resource Development. Suffield NWA is federal land managed by the Department of National Defence, and protection is afforded by both the Species at Risk Act and the Canada Wildife Act. The land tenure of these habitats will, in part, determine the long-term protection, if any, of these habitats.

Now that the presence of this species within the boundaries of the NWA has been established, more systematic surveys are needed to determine the distribution of the species and the size of the population, as well as normal fluctuations in population size from year to year. Although survey timing is difficult given the short flight period of adult Gold-Edged Gems, stratification of surveys should clearly be directed at active sand dune regions of prairie Canada.

1. COSEWIC 2006. COSEWIC assessment and status report on the Gold-edge Gem Schinia avemensis in Canada. Committee on the Status of Endangered Wildlife in Canada, Ottawa.

2. HARDWICK, D.F. 1996. A Monograph to the North American Heliothenthinae (Lepidoptera: Noctuidae). Published privately.

3. WOLFE, S.A., D.J. HUNTLEY, and J OLLERHEAD. 1995. Recent and late Holocene sand dune activity in southwestern Saskatchewan. In: Current research 1995-B. Geological Survey of Canada. p. 131-140.

4. HUGENHOLTZ, C. H. and S. A. WOLFE. 2005. Recent stabilization of active sand dunes on the Canadian prairies and relation to recent climate variations. Geomorphology 68:131-147.

5. VAN RIPER, L. and D.L. LARSON. 2009. Role of invasive Melilotus officinalis in two native plant communities. Plant Ecology 200:129-139.

6. HENDERSON, D.C., and M.A. NAETH. 2005. Multi-scale impacts of crested wheatgrass invasion in mixed-grass prairie. Biological Invasions 7:639650. 